\title{
NEUROLOGICAL DISORDERS ASSOCIATED WITH MALIGNANT DISEASE
}

\author{
W. Thomas Smith, M.D. (BIRM.) \\ Department of Pathology, University of Birmingham
}

Cerebral metastases occur in approximately $5 \%$ of all fatal cases of malignant disease (Willis, 1952) and the effects of discrete macroscopical deposits are well known. On the other hand, disorders of the nervous system resulting from either diffuse microscopical infiltration or other associated changes are less familiar and are the main concern of this survey.

In recent years it has been shown that carcinoma is sometimes associated with neuromuscular lesions which are not due to metastases. The resultant disorders are commonly termed carcinomatous neuropathy, myopathy or neuromyopathy, according to the site of the lesion. Although the adjective carcinomatous is also applicable to other neurological complications of carcinoma, such as those due to metastases, the term carcinomatous neuropathy is used in this paper with its current arbitrary non-metastatic connotation.

Diffuse carcinomatous infiltration of the brain, nerve roots or meninges may-produce a clinical picture which resembles carcinomatous neuropathy; this can only be established microscopically and precise diagnosis may therefore depend on pathological examination. Furthermore, neurological complications occasionally result from carcinoma emboli, from an associated thrombotic syndrome or from induced dietary or metabolic defects. Neurological lesions which are not due to gross metastases and sometimes complicate the diseases broadly classified as malignant reticuloses have also been described recently and merit consideration.

\section{Carcinomatous Neuromyopathy}

Neuromuscular syndromes occur in pure forms or in varying combinations, as has been shown in the detailed reports of Henson, Russell and Wilkinson (1954), Heathfield and Williams (1954) and Brain and Henson (1958). Although the disorders described below are distinguished for descriptive purposes, many gradations are found, depending on the relative involvement of brain, spinal cord, peripheral nerves and muscles, and there is no reason to regard them as different diseases. Clinical diagnosis depends on the dominant feature(s) present.

Cerebellar Cortical Degeneration (Brain, Daniel and Greenfield, 195I; Greenfield, 1954). The disease commonly runs a course of less than a year, occasionally only a few weeks and rarely more than two years. In published reports it has been associated with ' pelvic sarcoma' (Brouwer, I919), ovarian, bronchial, mammary and uterine carcinomas; our two pathologically confirmed cases had primaries in bronchus and colon.

The first symptom is usually unsteadiness of gait, which is followed by clumsiness of hands, vertigo, dysarthria, diplopia or nystagmus. Mental changes are often prominent and there may be pyramidal tract lesions, polyneuritic symptoms or involuntary movements. Arrest of the process but not remission is reported. The CSF may show an excess of cells, increased protein or a paretic Lange curve. Because of the rapid onset and course of the disease cerebellar tumour or multiple sclerosis is sometimes suspected.

Histologically there is generalized atrophy and loss of Purkinje cells throughout the cerebellum. Degeneration of the lateral and dorsal columns of the spinal cord, and meningeal and perivascular infiltration with lymphocytes have also been described. The clinical and pathological features which distinguish this from other cortical cerebellar atrophies are discussed by Victor, Adams and Mancall (1959).

Sensory Neuropathy (Denny-Brown, 1948). Characteristically this disorder reaches its maximum in a few weeks, but it may progress slowly over a period of months or even years. Clinically there is loss of joint and position senses and impairment of skin sensation without motor weakness. Tendon reflexes are diminished or absent, and severe root pains similar to the 'lightning pains' of tabes dorsalis may occur. Neurological symptoms and signs sometimes appear long before the associated neoplasm is detected, $3 \frac{1}{2}$ years elapsing in the case described by Dyck, Bailey and Olszewski (1958). 
Apart from the case with osophageal carcinoma reported by Dodgson and Hoffman (1953), the primary has always been bronchial.

Histologically the dorsal root ganglia show degeneration of nerve cells, many being replaced by nodules (' residual nodules') consisting of small, darkly staining cells. The central and peripheral processes of the degenerate sensory neurones undergo Wallerian degeneration, resulting in demyelination of the dorsal roots and columns of the spinal cord and patchy demyelination of the peripheral nerve sensory fibres. Our three cases also showed a variable degree of round-celled infiltration in the subarachnoid space over the cerebral and cerebellar hemispheres and in the perivascular spaces of the brain-stem. In one case there were 'residual nodules' in the oculomotor, trigeminal and dentate nuclei.

Polyneuritis (Sensory-Motor Neuropathy). This syndrome has always been associated with bronchial carcinoma. Lennox and Pritchard (1950) reported five cases with a peripheral neuritis of predominantly motor type, but with some sensory changes, the neuropathy always being the presenting clinical feature. Brain and Henson (1958) noted complete remissions in two out of five cases, in one instance six months before definite evidence of the carcinoma appeared; partial remissions have been described. Lea (1952) found evidence of polyneuritis in $2.2 \%$ of a series of 501 cases of bronchial carcinoma. One of our two cases showed patchy demyelination in the peripheral nerves and both showed chromatolysis in the anterior horn cells of the spinal cord. Other reported cases showed similar or no histological lesions. Coërs and Woolf (1959), using vital staining with methylene blue and also cholinesterase stains on muscle biopsies, found changes in the subterminal nerve fibres and subneural apparatus, and evidence of collateral reinnervation, in both polyneuritic and sensory disorders.

Neuromuscular Disorders. In this group there is often a progressive atrophic paresis of lower motor neurone type involving mainly the pelvic and shoulder girdles and proximal limb muscles. Tendon reflexes are diminished or lost in the affected areas and sometimes beyond it. Remissions may occur. Stem lesions (ptosis, diplopia, aphonia, palatal paralysis) and extensor plantar responses have been described. There may be pains in the limbs, cramps and paræsthesiæ, but objective sensory involvement is unusual.

Muscle weakness of either myopathic or myasthenic type may accompany the neuropathy. Amongst Brain and Henson's 15 patients with neuromuscular disorders eight showed myopathy without clinical evidence of neural lesions. Myasthenia with bronchial carcinoma was first reported by Anderson, Churchill-Davidson and Richardson (1953), oral neostigmine benefiting their patient; Mackenzie (1954), Shafar (1954), Borrelli and Keen (1954), Eaton and Lambert (1957) and Brain and Henson (1958) also described myasthenic cases. Croft (1958) found that patients with carcinomatous neuropathy but without overt myasthenia were hypersensitive to muscle relaxants.

The associated carcinomas have usually been bronchial, although Hart (1954) reported two cases, one with squamous carcinoma of antrum and the other with breast carcinoma, and amongst Brain and Henson's patients were 'examples of rectal and prostatic growths'. Two cases with bronchial carcinoma examined in this Department showed clinical features resembling myasthenia gravis and motor neurone disease respectively; a third predominantly myopathic case was associated with hepatic carcinoma and hæmochromatosis, but is only tentatively included in this category because of these complex findings.

The site of the lesion responsible for muscle wasting has not been found from biopsy or necropsy studies and Brain and Henson suggested that the disturbances may arise at more than one 8 level in the neuromuscular system. Histology has shown non-specific muscle atrophy, degeneratione and loss of neurones in the spinal cord and brain-? stem, and loss of fibres in the peripheral nerves.

The differential diagnosis may be difficult and includes dermatomyositis, polymyositis, myopathy of late onset, myasthenia gravis and motor neurone disease.

Mental Changes. These may be the first indication of carcinomatous neuropathy and occasionally persist alone. More commonly they are associated with other evidence of neuropathy, especially cerebellar dysfunction. Brain and Henson described 17 patients with mental disturbances and ro of these had cerebellar symptoms. Meerloo (1944) described nine patients with mental disorders and 'pulmonary carcinoma'; several probably had peripheral neuritis. Charatan and Brierley (1956), who reported three cases of bronchial carcinoma with toxic confusional psychosis, considered that extensive liver metastases were a causative factor. But McGovern, Miller and Robertson (1959) described two cases with mental changes in which there were no liver metastases and I have also examined a similar case. Savage and Noble (1954) reported two cases of pancreatic carcinoma with a psychiatric illness, reviewed the literature and found that 26 similar cases had previously been described; the mental changes 
are apparently not related to interference with insulin secretion.

Mixed Disorders. In some patients gradations between the above groups occur, a dominant clinical picture does not emerge and precise classification is difficult. Cerebellar dysfunction is usually present in such patients, but is less severe than in the first group. Other features are superimposed, such as peripheral neuritis, neuromuscular and upper motor neurone lesions, bulbar palsies, involuntary movements and disturbances of sensation. In the mixed cases described by Brain and Henson inflammatory changes were a noteworthy pathological change. McCaughey and Millar (1955) reported a case in which there was sensory neuropathy, involuntary movements, dorso-lateral demyelination in the spinal cord and calcified concretions in the dorsal-root ganglia.

\section{Diffuse Carcinomatous Infiltration of the Nervous System}

Diffuse infiltration of the spinal nerve roots and peripheral nerves with metastatic carcinoma can present clinically as polyneuritis (Selinsky, 1930; Barron, Rowland and Zimmerman, 1960) and resemble the polyneuritic variety of carcinomatous neuropathy. The ultimate diagnosis may depend upon histological examination, macroscopical changes being absent in some cases.

Clinical signs may also result from diffuse microscopical infiltration of the brain with carcinoma cells. Three cases associated with bronchial carcinoma were reported by Madow and Alpers (I95I) as ' encephalitic metastatic carcinoma ' and there were no naked-eye changes. Isolated clumps of anaplastic carcinoma cells, especially when derived from an 'oat-cell' bronchial carcinoma, can be difficult to identify, and the pathologist may find it hard to decide whether lesions are due to diffuse infiltration or non-metastatic carcinomatous neuropathy. With Dr. A. G. Whitfield (Smith and Whitfield, 1955) I reported a case of carcinomatous sensory neuropathy in which it seemed that the cellular nodules in the spinal ganglia might include anaplastic carcinoma cells, and I have since seen two similar cases.

The sub-arachnoid space is sometimes diffusely infiltrated with carcinoma cells (" carcinomatous meningitis ') which have not spread from adjacent neural or osseous deposits. Fischer-Williams, Bosanquet and Daniel (1955) found that the main clinical features were vague ill-health followed by neurological symptoms and signs (headache, meningism, fits, mental deterioration, visual failure, loss of tendon jerks, cranial nerve palsies) which may appear suddenly and progress rapidly. Examination of the CSF sometimes shows malignant cells or a reduced sugar content. Carcinomatous neuropathy may again be simulated. Thus, Alpers and Smith (1938) and Alajouanine, Boudin, Nick and Contamin (1950) described polyneuritic cases and Greenfield (1938) noted dementia as a presenting clinical feature. Fischer-Williams et al. (r955) stated that the optic nerve degeneration in their cases might be related to the degenerative lesions described in carcinomatous neuropathy. The way in which carcinoma cells reach the subarachnoid space in 'carcinomatous meningitis' is undecided: perineural lymph-borne infiltration, retrograde venous spread and direct hæmic metastasis have all been suggested.

Although the gastro-intestinal tract and bronchus are the commonest site of the primary growth, reports indicate that most carcinomas can involve the leptomeninges in this way.

\section{Neurological Complications of Emboli of Carcinoma Cells}

Cerebral softening due to blood-borne neoplastic emboli is recorded by Thompson and Evans (1929), Storjohann (1932), Eason (1950), Madow and Alpers (1952), Miller and Jackson (1954) and others. Smith and Whitfield (1954) found focal softenings related to microscopical carcinoma emboli in the brain of a woman dying $7 \frac{1}{2}$ yearso after radical excision of a breast carcinoma; in filtrative metastases were not present. A case of lepto-meningeal carcinomatosis described by Smith (1957) showed carcinoma emboli occluding small arteries penetrating the spinal cord, with resultant focal myelomalacia.

Smith (1957) also made a detailed histological study of 27 macroscopically normal brains from patients suffering from carcinoma who had not showed clinical evidence of neurological disease. Two out of I I cases of bronchial carcinoma showed many intra-vascular carcinoma emboli, with minimal extra-vascular infiltration. One out of six cases of breast carcinoma showed a single focus of leptomeningeal infiltration. The remaining ro cases (two prostatic, three gastric, two uterine, two vesical and one pancreatic carcinomas) did not show cerebral deposits. Although the number of cases examined in this series was limited because of the work involved in examining each brain in sufficient detail, it seems probable that more than $10 \%$ of fatal cases of bronchial carcinoma will show intra-cerebral carcinoma emboli which are clinically latent. Clinical signs may, however, occasionally be produced in this way, as illustrated by another case examined by Smith (1957). Bulbar palsies and ataxia led to a tentative diagnosis during life of primary brain tumour, but when a macroscopically normal brain and an unsuspected bronchial carcinoma were found at necropsy the 
diagnosis was changed to carcinomatous neuropathy. Histology subsequently showed that abundant carcinoma emboli and minute metastases in the cerebral cortex, brain-stem and cerebellum were responsible for the clinical signs.

Neurological complications may also result from massive carcinoma emboli, sometimes recognizable macroscopically, and I have seen three such cases. In the first case a carcinoma embolus was displaced into a pulmonary vein during pneumonectomy for bronchial carcinoma and caused a fatal cerebral softening. In the second case a bronchial carcinoma infiltrated along a pulmonary vein into the left auricle, forming a necrotic intra-auricular mass, from which a cerebral embolus originated. In the third case a fragment of renal carcinoma, liberated into the venous system during nephrectomy, passed into the left auricle through a patent foramen ovale and a paradoxical tumour embolus finally occluded a middle cerebral artery.

\section{Cerebral Lesions Associated with Malignant Thrombosis}

Trousseau (1873) first described recurrent venous thrombosis as a sign of obscure carcinoma; recently it has been found that arterial occlusion may also occur in such cases (Oelbaum and Strich, 1953; Williams, 1954; Fisher and Baird, 1956). The thrombosis is not attributable to recumbency, or invasion of or pressure on blood-vessels by the carcinoma. Cerebral thrombosis has occasionally been mentioned in previous reports. Some cases also develop non-bacterial thrombotic vegetations on the heart valves (Sproul, 1938; Smith and Yates, 1955). The syndrome most commonly occurs with pancreatic carcinoma, but has also been found with many other primaries, particularly bronchial and gastro-intestinal.

Smith (1957) found that neurological disorders attributable to the malignant thrombosis syndrome occurred in ro out of 993 consecutive fatal cases of carcinoma. The primary carcinomas were as follows: four pancreatic, two uterine, two gastric, one mammary, one bronchial. In six cases neurological complications (hemiplegia, convulsions, involuntary movements, ataxia, mental changes) first appeared within a week of death and in the other four cases, four, six and twenty weeks, and four years before death. Multiple venous and/or arterial thromboses of major extra-cerebral vessels were found in all cases and coincident atherosclerosis predisposed to arterial occlusion. In six cases neuropathy resulted from microthrombosis of the cerebral arteries or veins and in four cases from gross occlusion of the internal carotid artery or its proximal branches. In five cases microthrombosis was also found in the myocardium, spleen, liver, lungs or adrenals. Four cases (three pancreatic, one gastric) showed cardiac vegetations. McDonald and Robbins (1957) and Barron, Siqueira and Hirano (1960) drew attention to the clinical significance of non-bacterial thrombotic endocarditis and confirmed the finding of Adams (1955) that cerebral embolism secondary to it may be the first indication of an occult carcinoma.

In the malignant thrombosis syndrome some microthrombi appear to be arrested embolic fragments of cardiac vegetations, although autochthonous microthrombosis also occurs in cases without vegetations. The microthrombi and the cardiac vegetations consist of material which is probably a mixture of fibrin, altered fibrin and fused platelet masses; they are not superimposed on carcinoma emboli (Smith, 1957). There is a morphological similarity between the microthrombi seen in this syndrome and in thrombotic microangiopathy (' platelet thrombosis syndrome').

The occlusion of small cerebral blood vessels results in focal areas of degeneration of variable size which have no specific features. Recent lesions consist of pale zones of coagulative necrosis; older lesions show infiltration with lipophages and are eventually transformed into gliotic scars. Vascular congestion and perivascular hæmorrhages are frequently found when veins are occluded.

Neurological disorders resulting from the malignant thrombosis syndrome deserve wider recognition and may be the first indication of an occult carcinoma.

\section{Neuropathy Due to Dietary or Metabolic Defects Induced by Carcinoma}

Neuropathy induced in this way needs only brief mention. Nutritional neuropathy (particularly Wernicke's encephalopathy) associated with gastro-intestinal carcinoma is a well-known example. Neoplastic destruction of organs essential to metabolism may also result in neurological disorders, e.g. hepatic encephalopathy with primary or secondary liver carcinoma. There is, however, no reason to believe that any of the cases of carcinomatous neuropathy studied in this Department resulted from similar dietary or metabolic defects.

\section{Neurological Complications of Malignant Reticuloses}

Changes in the brain, spinal cord and peripheral nerves which result from either diffuse infiltration or compression by osseous or dural metastases may occur in leukæmia, lymphosarcoma, reticulosarcoma, Hodgkin's disease and multiple myeloma (see Sparling, Adams and Parker, 1947; Clarke, I954; Morrell, 1958; Williams, Diamond and Craver, 1958; Hunt, Bouroncle and Meagher, 
1959; Barron et al., 1960, and others). In some cases the affected areas appear normal macroscopically. Cerebral hæmorrhage and œdema are also frequent causes of neurological complications in leukæmia (Hunt et al., 1959).

Demyelination in the brain, spinal cord and peripheral nerves, which is unrelated to tumour infiltration, has recently been described in this group of diseases and is of particular interest. Victor, Banker and Adams (1958) described five cases of demyelinating polyneuropathy associated with multiple myeloma and found that it resembled sensory-motor carcinomatous neuropathy. Cameron, Howell and Hutchison (1958) described demyelination of the peripheral nerves in Hodgkin's disease, as did Hutchinson, Leonard, Maudsley and Yates (1958), who also found demyelination in the spinal cord. Cerebral disorders associated with demyelination in Hodgkin's disease and lymphatic leukæmia were reported by Åström, Mancall and Richardson (1958) and Cavanagh, Greenbaum, Marshall and Rubinstein (1959) and in lymphosarcoma by Lloyd and Urich (1959). The cerebral demyelination in most cases was multi-focal, tended to become confluent and was associated with bizarre changes in the glial nuclei. The clinical picture may closely resemble acute Schilder's disease and in one of the cases of Cavanagh et al. (1959) the pathological findings were those of Schilder's disease. There is no evidence that demyelination in the malignant reticuloses results from treatment with radiotherapy, radiomimetic drugs or any other form of therapy.

\section{Discussion}

It is clear that some neurological disorders associated with carcinoma result from diffuse metastatic infiltration of various parts of the nervous system and are only recognizable histologically. In other cases occlusion of blood vessels of microscopical size by carcinoma emboli produces focal lesions. The reason why such micro-emboli do not develop into distinct macroscopical metastases and either remain intra-vascular or else spread diffusely in the neural tissue or meninges is a fundamental question related to factors such as the invasive properties of tumour cells and stromal response. The important practical point is that the spread of tumours in the nervous system is so protean that even in the absence of naked-eye changes histological study is usually obligatory before making a definite diagnosis of carcinomatous neuropathy. Fatal cerebral infarction due to gross tumour embolism, although interesting, is apparently a chance event which may occur spontaneously or as a complication of cancer surgery.
The cause of the non-metastatic neuropathies $\stackrel{0}{0}$ associated with malignant disease remains obscure. ‡ It has been suggested that carcinomatous neuro- $\bar{z}$ pathy may be due to 'carcinotoxins', vitamin $\stackrel{\odot}{\circ}$ deficiencies or metabolic disorders conditioned by $c$ the carcinoma, virus infection, endocrine abnor- $\vec{F}$ malities or the production of auto-antibodies to $\stackrel{5}{?}$ nerve tissue. Other possibilities are that the carcinoma and the neuropathy are induced by a $\frac{\bar{\sigma}}{\bar{D}}$ common ætiological agent, or even that multiple $\vec{\sigma}$ factors are concerned. All of these hypotheses are $\varnothing$ speculative and no single explanation will suffice in all cases.

Cerebral demyelination complicating malignant reticuloses differs clinically and pathologically from $\vec{\omega}$ the cerebral lesions described in carcinomatous neuropathy, although there are similarities as far as peripheral nerve involvement is concerned. Theories explaining reticulotic neuropathy have. been similar to those advanced in carcinomatous î neuropathy, but it is debatable whether the pathogenesis is similar in both groups.

The association of carcinoma with diseases other than neuropathy, such as polymyositis, dermatomyositis, scleroderma, acanthosis nigricans, pur $-\vec{z}$ pura and thrombosis, is now well known. The pathological effects in some cases can be complex, $\overrightarrow{\mathscr{O}}$ as illustrated by the cerebral lesions resulting from the syndrome of carcinoma and thrombosis. Te? minology is not yet standardized and Walton and Adams (1958) considered that there are ground for considering dermatomyositis, polymyositis and myopathy in patients with malignant disease col- ٌٌ lectively rather than as separate syndromes. The $\stackrel{\varnothing}{\varnothing}$ nature of the connection between cancer, neuro- $\overrightarrow{\vec{D}}$ pathy and diseases of the connective tissues is a 3 formidable probłem, the investigation of which $\supset$ could well be rewarding and disclose factors which are important both in carcinogenesis and in main- 흘 taining the form and function of neural and other tissues.

\section{Summary}

I. Various neurological disorders associated with malignant disease are discussed, including: 옥 non-metastatic carcinomatous neuropathy; com- $\rightarrow$ plications resulting from diffuse carcinomatous or reticulotic infiltration, from carcinoma emboli, or N from an associated thrombotic syndrome; and demyelination associated with malignant reticu- $\tilde{N}$ loses. The effects of discrete macroscopical meta- $\omega$ stases are not considered in this survey.

2. Etiological mechanisms are only briefly $\bullet$ mentioned because at the present time these are $\Phi$ conjectural. It is stressed that there may be a $\stackrel{?}{+}$ clue in the non-metastatic disorders to factors important both in carcinogenesis and in maintain- $\frac{O}{\mathbb{D}}$ ing the integrity of neural and other tissues. 


\section{REFERENCES}

Adams, R. D. (1955): Case Record 41491 of Mass. Gen. Hosp., New Engl. F. Med., 253, 1030.

Alajouanine, T., Boudin, G., Nick, J., and Contamin (1950): Polyradiculonévrite Généralisée Rapidement Mortelle: Méningite Cancéreuse et Infiltration Directe des Racines au Contact des Méninges Malades, Rev. neurol., 82, 40.

Alpers, B. J. and Smith, O. N. (1938): Carcinomatosis of the Meninges of the Spinal Cord and Base of the Brain, without Involvement of the Parenchyma, Secondary to Carcinoma of the Lung, Amer. F. Cancer, 32, 36r.

Anderson, H. J., Churchill-Davidson, H. C., and Richardson, A. T. (1953): Bronchial Neoplasm with Myasthenia, Lancet, ii, 1291.

Åström, Karl-Eric, Mancall, E. L., and Richardson, E. P. (1958): Progressive Multifocal Leucoencephalopathy, Brain, 8r, 93.

Barron, K. D., Rowland, L. P., and Zimmerman, H. M. (1960): Neuropathy with Malignant Tumour Metastases, F. nerv. ment. Dis., I3I, ro.

-, Siqueira, E., and Hirano, A. (1960): Cerebral Embolism Caused by Non-bacterial Thrombotic Endocarditis, Neurology, ro, 391 .

Borrelli, V. M. and KeEN, H. (1954): Bronchial Neoplasm with Myasthenia, Lancet, i, 315.

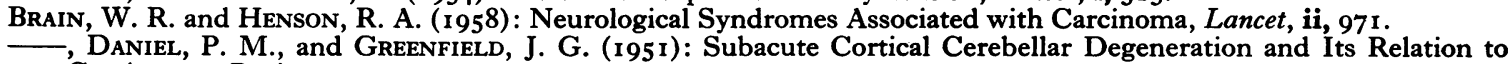
Carcinoma, Brain, I4, 59.

Brouwer, B. (r919): Cited by Greenfield, J. G. (1954), Neurol. Zbl., 38, 674.

Cameron, D. G., Howell, D. A., and Hutchison, D. L. (1958): Acute Peripheral Neuropathy in Hodgkin's Disease, Neurology, 8, 575.

Cavanagh, J. B., Greenbaum, D., Marshall, A. H. E., and Rubinstein, L. J. (1959): Cerebral Demyelination Associated with Disorders of the Reticuloendothelial System, Lancet, ii, 524.

Charatan, F. B. and Brierley, J. F. (1956): Mental Disorder Associated with Primary Lung Carcinoma, Brit. med. f., i, 765 .

Clarke, E. (1954): Cranial and Intracranial Myelomas, Brain, 77, 61.

Cokrs, C. and Woolf, A. L. (1959): The Innervation of Muscle. Ist Edition. Oxford: Blackwell.

Croft, P. B. (1958): Abnormal Responses to Muscle Relaxants in Carcinomatous Neuropathy, Brit. med. F., i, r 81.

DenNY-Brown, D. (1948): Primary Sensory Neuropathy with Muscular Changes Associated with Carcinoma, $\mathcal{F}$. Neurol. Neurosurg. Psychiat., I1, 73.

Dodgson, M. C. H. and Hoffman, H. L. (1953): Sensory Neuropathy Associated with Carcinoma of the Oesophagus: Report of a Case, Ann. intern. Med., 38, 130.

Dyck, P. J., Balley, A. A., and Olszewski, J. (1958): Carcinomatous Neuromyopathy: A Case of Sensory Neuropathy and Myopathy with Onset $3 \frac{1}{2}$ Years before Clinical Recognition of Bronchogenic Carcinoma, Canad. med. Ass. $\mathcal{F}$., 79, 913.

Eason, E. H. (1950): A Case of Cerebral Infarction due to Neoplastic Embolism, F. Path. Bact., $62,454$.

EATON, L. M. and LAMBeRT, E. H. (1957): Electromyography and Electric Stimulation of Nerves in Diseases of Motor Unit: Observations on Myasthenic Syndrome Associated with Malignant Tumours, F. Amer. med. Ass., I63, 1117.

Fischer-Williams, Mariella, Bosanquet, Frances, D., and Daniel, P. M. (1955): Carcinomatosis of the Meninges: A Report of 3 Cases, Brain, 78, 42.

FISHeR, E. R. and BAIRD, W. F. (1956): The Nature of Arteriolar and Capillary Occlusion in Patients with Carcinoma, Amer. F. Path., 32, 1185 .

Greenfield, J. G. (1938): In-Discussion of the Presenile Dementias: Symptomatology, Pathology and Differential Diagnosis, Proc. roy. Soc. Med., 31, 1450.

(1954): The Spinocerebellar Degenerations. Ist edition. Oxford: Blackwell.

Hart, P. L. DE V. (1954): Carcinoma Complicated by Proximal Motor Neuropathy Due to Vitamin B Deficiency, Brit. med. F., i, 606.

Heathfield, K. W. G. and Williams, J. R. B. (1954): Peripheral Neuropathy and Myopathy Associated with Bronchogenic Carcinoma, Brain, 77, 122.

Henson, R. A., Russell, Dorothy S., and Wilkinson, Marcia (1954): Carcinomatous Neuropathy and Myopathy-a Clinical and Pathological Study, Brain, 77, 82.

Hunt, W. E., Bouroncle, B. A., and Meagher, J. N. (1959): Neurologic Complications of Leukæmias and Lymphomas, F. Neurosurg., 16, 135 .

Hutchinson, E. C., Leonard, B. J., Maudsley, C., and Yates, P. O. (1958): Neurological Complications of the Reticuloses, Brain, 8r, 75.

LEA, A. J. (1952): A Survey of 501 Cases of Bronchogenic Carcinoma, Thorax, 7, 305.

Lennox, B. and Pritchard, S. (1950): The Association of Bronchial Carcinoma and Peripheral Neuritis, $Q u a r t$. $\mathcal{~}$. Med., r9, 97.

Lloyd, O. C. and URICH, H. (1959): Acute Disseminated Demyelination of the Brain Associated with Lymphosarcoma, Lancet, ii, 529.

MackenzIe, I. (1954): Bronchial Neoplasm with Myasthenia, Lancet, i, 108.

Madow, L. and Alpers, B. J. (1951): Encephalitic Form of Metastatic Carcinoma, Arch. Neurol. Psychiat. (Chicago), 65, 161 .

- - (1952): Cerebral Vascular Complications of Metastatic Carcinoma, Y. Neuropath. exp. Neurol., r1, 137.

McCaughey, W. T. E. and Millar, J. H. D. (1955): Nervous Degeneration in Malignant Disease, Lancet, ii, 365.

McDonald, R. A. and RobBins, S. L. (1957): The Significance of Non-bacterial Thrombotic Endocarditis: An Autopsy and Clinical Study of 78 Cases, Ann. intern. Med., 46, 255.

McGovern, G. P., Miller, D. H., and Robertson, E. Elizabeth (1959): A Mental Syndrome Associated with Lung Carcinoma, Arch. Neurol. Psychiat. (Chicago), 81, 341.

Meerloo, A. M. (1944): The Initial Neurologic and Psychiatric Picture of Pulmonary Growth, F. Amer. med. Ass., ras, $55^{8}$. 
Miller, A. A. and Jackson, F. B. (1954): Gross Arterial Embolism by a Myxosarcoma of Pulmonary Origin, Y. Pathi Bact., 68, $22 \mathrm{I}$.

MoRRELL, R. M. (1958): Cranial Neuropathy in Advanced Hodgkin's Disease, Dis. nerv. Syst., 19, 26r.

Oelbaum, M. H. and STRICH, Sabina J. (1953): Thrombophlebitis Migrans and Carcinoma of the Body and Tail of Pancreas, Brit. med. $\mathcal{Y}$., ii, 907.

Savage, C. and Noble, D.' (1954): Cancer of the Pancreas: Two Cases Simulating Psychogenic Illness, f. nerv. ment. $\mathrm{C}^{\mathrm{C}}$ Dis., 120, 62.

SELINSKY, H. (1930): Metastatic Carcinoma of the Brain and Cord Simulating Polyneuritis, Arch. Neurol. Psychiat. $\overrightarrow{\overrightarrow{\vec{N}}}$ (Chicago), 23, 197.

SHAFAR, J. (1954): Bronchial Neoplasm with Myasthenia, Lancet, i, ro9.

SMITH, J. P. and YATES, P. O. (1955): The Thrombotic Syndrome Associated with Carcinoma, F. Path. Bact., 70, II I.

Smith, W. T. and Whitfield, A. G. W. (1954): Intravascular Microembolic Carcinomatosis as a Cause of Purpura. Report of a Case associated with Focal Histological Lesions in the Nervous System, Brit. $\mathcal{F}$. Cancer, 8, 97.

(1955): Malignant Sensory Neuropathy, Lancet, $i, 282$. (1957): Studies on the Association of Carcin
M.D. Thesis. University of Birmingham.

Sparling, H. J. JR., AdAMS, R. D., and PARKeR, F. (1947): Involvement of the Nervous System by Malignant $\overrightarrow{0}$ Lymphoma, Medicine, 26, 285.

Sproul, E. E. (1938): Carcinoma and Venous Thrombosis: The Frequency of Association of Carcinoma in the Body or Tail of the Pancreas and Multiple Venous Thromboses, Amer. F. Cancer, 34, 566.

Storjohan, K. R. (1932): Cited by Madow, L. and Alpers, B. J. (1952), see above, Frankfurt. Z. Path., 43, 80.

Thompson, T. and Evans, W. (1929-30): Paradoxical Embolism, Quart. F. Med., 23, 135.

Trousseau, A. (1873): Clinique médicale de l'Hôtel-Dieu de Paris, 3, 695. 4th edition. Paris: Baillière.

Victor, M., BANKRR, BETTY Q., and ADAMs, R. D. (1958): The Neuropathy of Multiple Myeloma, $\mathcal{F}$. Neurol. Neurosurg

Psychiat., 21, 73.
, ADAMS, R. D., and MANCALl, E. L. (1959): A Restricted Form of Cerebellar Cortical Degeneration Occurring in Alcoholic Patients, Arch. Neurol. (Chicago), 1, 579.

Walton, J. N. and Adams, R. D. (I958): Polymyositis. Ist edition. Edinburgh: E. \& S. Livingstone.

Williams, A. A. (I954): Malignant Disease Associated with Vascular Phenomena, Brit. med. $\mathcal{Y}$., ii, 82.
Williams, H. M., Diamond, H. D., and Craver, L. F. (1958): The Pathogenesis and Management of NeurologicaP Complications in Patients with Malignant Lymphomas and Leukæmia, Cancer, 11, 76.

Willis, R. A. (1952): The Spread of Tumours in the Human Body. 2nd edition. London: Butterworth.

\section{ERRATUM}

' THE THiRd Stage Of LAbouR', by F. Denny, A. E. B. Matthews, and R. M. Wild February issue 196r. Page 86, Table 5:

Page 87, Table 9:

Column giving totals-for 1,167 read 1,815; for 1,047 read 1,127; for 2,214 read 2,942.

Total of control group-for 2,942 read I,8 5 . 